\title{
Smart Mobile Control System in Managing Drinking Water Crisis Using Internet of Things
}

\author{
Azar Astanehparast, Majid Haghparast* and Sara Najafzadeh \\ Department of Computer Engineering, Yadegar-e-Imam Khomeini (RAH) Shahre \\ Rey Branch, Islamic Azad University, Tehran, Iran \\ *haghparast@iausr.ac.ir
}

\begin{abstract}
Water crisis management using smart and suitable solutions can be effective in speeding the unit of relief and control of water and wastewater accidents, as well as reducing the number of incidents in the urban water supply network. The use of the vast applications of the Internet of things and the mobile platform and the association of this technology with the water industry lead to the maximum use of the capacity of this technology in smart management of drinking water crisis. Further, determining the priority in dealing with the dangers and minimizing damage are the major concerns of crisis management in metropolises. Urban water management is very important in dealing with the crisis. In this paper, the Internet of Things is considered as one of the best new technologies in drinking water disaster management and urban water networks, with the approach to improve decision-making speed, labor division management and cost reduction. The overall goal of this project is to provide a comprehensive model that can coordinate the process of water accident management using the Internet of Things.
\end{abstract}

Keywords: Internet of Things, Water Management, Water events

\section{Introduction}

The events of urban water supply networks are one of the most important factors in contamination of drinking water network and losses of material capital. Therefore, water crisis management using smart and suitable solutions can increase the speed of the unit of relief and control of water and wastewater accidents and also reduces the number of urban water supply network accidents. Further, the use of the vast applications of the Internet of things and the mobile platform and the association of this technology with the water industry lead to the use of the maximum capacity of this technology in smart management of drinking water disaster crisis. Major challenges in drinking water disaster management and urban water supply networks include the speed of decision-making on the type of accident, the labor division management, the dispatch of an executive division based on priority, the selection of the supervisor of the work and the identification of the organs involved in accidents and information on status of accident Water supply site network and so on. Using traditional methods in disaster management and updating technical information in other decision-making systems such as telemetry, geographic information system (GIS), preventive maintenance (PM), etc., or making decisions about each of the above variables will lead to problems and inconsistencies. Therefore, considering the problems and risks in this field (cost and time consumption and customer dissatisfaction), it can use alternative technologies such as the use of mobile phones with the focus on the technology of internet of things can be used. The Internet of things generally refers to many of the things and environments around us that connect to the Internet and can be

Received (March 7, 2018), Review Result (May 11, 2018), Accepted (June 19, 2018)

* Corresponding Author 
controlled and managed by apps on their smartphones and tablets; It can also enhance the management of operations in the information process and reduce the time of the implementation of operations, and coordinate and synchronize intra-organization and inter-organization interactions in accidents and incidents [1]. With the development of smart technologies, the development of communication networks and the Internet, the development of sensors and sensor networks, extensive efforts have been made to use these technologies to improve the process of various management and operational processes. In 1999, Quinn Ashton used the term "Internet of Things" in a lecture on Supply Chain Management for the first time. He believed that because of the advances made in computing, the Internet, and the production rate of data by smart devices, our way of life in the physical world needs to be revised [2]. A closer look at the IOT phenomenon shows that the two pillars of the Internet of Things are the concepts of the "Internet" and "objects" that require more clarity. Although it seems that anything that has Internet connectivity is in the category of "things," but this concept is used to embrace a more general set of entities. Smart devices, sensors, humans, and any other thing that is aware of the subject are able to communicate with other entities and accessible at any time or anywhere. This concept means that things need to be available without any time or place restrictions. The ubiquitous connection is the vital requirements of the Internet of Things. To realize that, applications need to support a variety of communication equipment and protocols, from small sensors that can sense and report the desired agent, to powerful servers on the far end Which are used for data analysis and knowledge extraction. It also requires the integration of mobile devices such as edge devices such as smart routers and hubs, and humans in the cycle as controllers [3]. Over time, the Internet of Things is expected to bring significant applications to help quality of life and the growth of the global economy in business.

The rest of the paper is organized as follows: In Section 2 the literature review is briefly introduced. Section 3 presents the research methodology and Section 4 belongs to the proposed plan. Simulation results are provided in Section 5. Finally, in Section 5 conclusion is given. A comprehensive list of references is also provided.

\section{Literature Review}

In line with the goals of the Iranian power industry to create a smart energy network, as a first step, the National Intelligent Energy Metering and Energy Management Plan (Fahaam) is defined as the Smart Energy Measurement System for Iran and its specifications according to the needs of the Ministry of Energy and Oil by Organization of Energy Productivity of Iran was developed. Within the framework of this plan, a smart meter will be installed for a million subscribers in six provinces of Iran. According to the authorities, the plan needs 60,000 billion Rials to be implemented. A wide range of applications in the Internet of things are appeared in the industry. The purpose of the Internet of things is to connect things to various things across the network. It integrates heterogeneous systems and devices as a key technology. The service-oriented architecture supports the Internet of things. The use of service-oriented architecture in research areas such as cloud computing, wireless networks and vehicle networks has been successful. For the Internet of things, it has been presented based on multimode-based layering technology. In 2013, Banu and his colleagues designed the expert system based on the Internet of Things. The system has been integrated into a larger Internet of things architecture, which consists of three main layers: the perception layer (or sensor), the network layer, and the layer of Application software. In the perception layer, information is collected from things and transmitted through the network layer to the applied layer. In the application layer, two types of software are provided. These two types of software are connected to the expert system, which returns the output based on received inputs. Images are uploaded to the system via special software and process the expert system of this 
input. One can decide on the answer given by the expert system [4]. In 2016, Santos and colleagues have presented an Internet-based mobile gateway for mobile health scenarios (m-Health). The gateway automatically collects information about the patient, such as location, heart rate, and potential miscarriage, and sends collected information to caregivers promptly. The authors of this reference have used AMBRO technology platform, which have developed this platform in their previous studies. AMBRO supports the integration of Intelligent Personal Assistants (IPA) with ubiquitous communications technologies. AMBRO brings him various aspects of life to help the user in various ways and offers. With the help of an AMBRO personal assistant, users can access their favorite Web services (such as finding nearby restaurants, consulting weather information, etc.,), and consult about their sensor data that is in use (like temperature), change the behavior of intelligent things that are in the environment (e.g., among objects, turn off the only air conditioning). On the other hand, because in communication scenarios, whenever equipment is constantly changing its position, it is essential to use a mobile gateway to direct traffic. One possible way to enable such scenarios is to use mobile as a mobile gateway. Mobile application software has been developed by reference authors for use on the Android operating system, called with a mobile gateway AMBRO. The AMBRO Mobile Gateway is a software application that allows the Personal Assistant AMBRO to the IPA Supervisor to take care of the health indicators of the patient under his care. In order to create a fully functional system, the supervisor should always have a smartphone with the AMBRO mobile gateway software installed on it. This software allows both sides of the user (supervisor and supervisees) to control three different monitoring services that use Body network sensors (BSNs).

One of the Monitoring services is a location monitoring service that uses a smartphone GPS receiver to determine the exact location of the supervisee location. Two other Monitoring services are the Heart Rate Monitor and fall detection system. The data collected by these services will be sent to the AMBRO cloud via a mobile gateway. Information is stored and processed in the cloud, and alerts are sent to the caretaker in case of any malformations. Both supervisor and supervisee can use the software after passing through the authentication stage [5]. The Internet of things has been used in fire extinguishers. Internet of things has helped to identify the potential fire and alert them in this process. In China, using RFID tags and bar codes, they have gained a lot of help with connecting firefighting equipment to prevent it from spreading. Using RFID and mobile tags and smart video cameras, sensor networks and wireless communications, automatic detection has helped for this incident, and fire warning and emergency rescue if necessary, have improved the potential damages to the environment. Researchers in China have made automatic alert systems to enhance their firefighting management in China. The software infrastructure of the Internet of things itself consists of a platform and application support transmission layer in the form of a five-layer architecture. Its challenges in firefighting are the creation of standards for its implementation [6].

\section{Research Methodology}

In this research, the conditions of the four variables should be considered, therefore, in order of importance and role in this topic, are examined as follows: 1- The Internet of Things, 2- Definition of drinking water crisis and accidents, 3. Smart control, 4. Mobile platform.

First, the architecture of the Internet of things layers in the water accident management cycle is specified and the specificity and the process of the proposed model are examined, and we reach to conclusion by analyzing the data collected through database information, hardware equipment of water network and accident database. The data collection is carried out through the database information of the hardware equipment of the water network and the accident database, and a specialized statistical population in this area 
includes a range of ICT specialists, water crisis management experts and civil engineers. Considering different types of reference model of internet of things observed in Figure 1 and their comparison with each other as well as study on adapting different stages of signal transmission process by equipment of a water supply network with different layers, we select 5-layer reference model due to more matching with the considered process. Further, as mentioned earlier, the 5-layer reference architecture in China has been used to alert the fire service and signaling at the time of the incident, and because of the similarity of our scenario, we also use the above architecture.

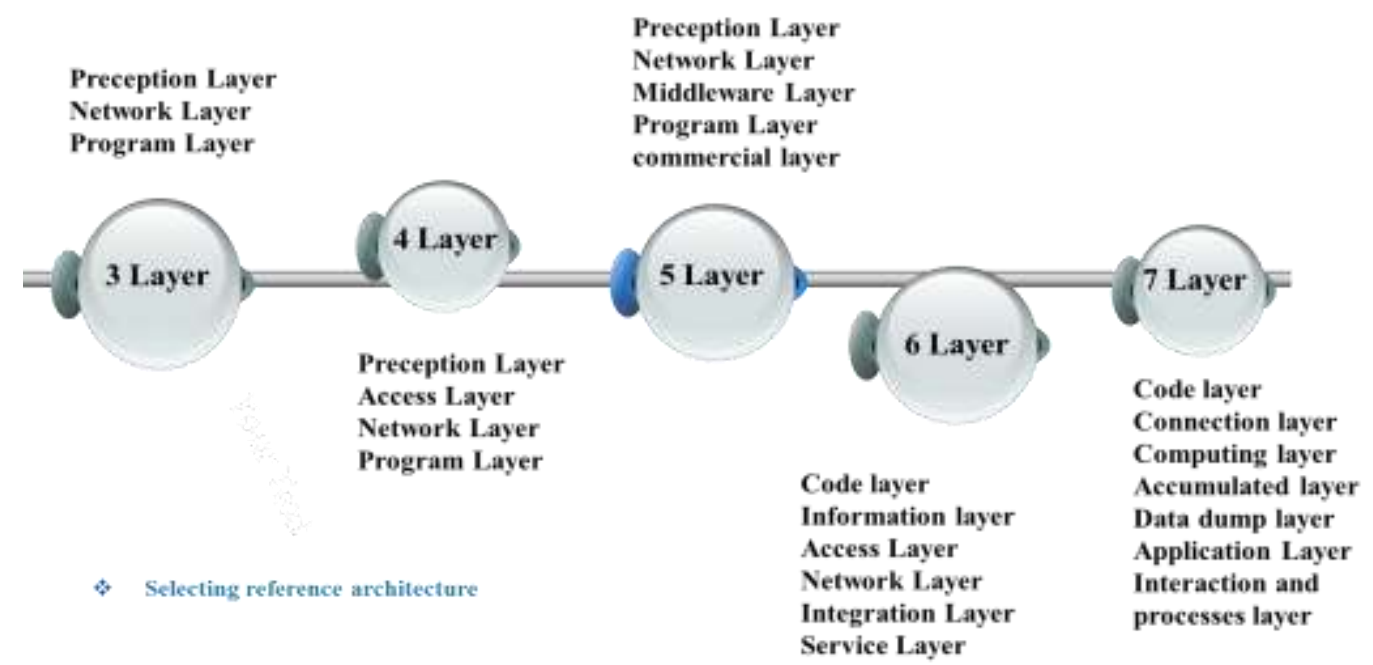

Figure 1. Different Types of Architecture in the Internet of Things

The use of the 5-layer Reference Model for internet of things in the water supply network, as shown in Figure 2, is proposed as follows.

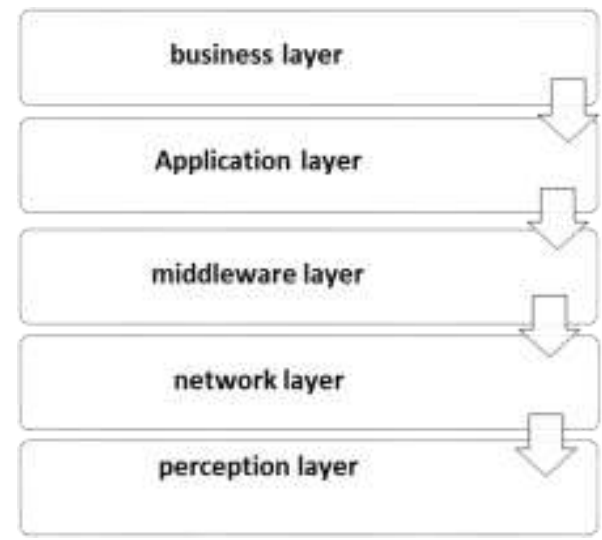

\section{Figure 2. Five Layer Architecture [7]}

Considering that our architecture for intelligent water accident management using mobile phone consists of the following five layers, this section describes the performance of each of the layers of the proposed model.

Business layer: This layer is directly related to the user and is used to display the information.

Application layer: In this layer, sensor information is categorized as display. 
Middleware layer: In this layer, sensor information to send to the network are placed in its own packages.

Network layer: In this layer, sensor information is sent with regard to security and network packets.

Perception layer: In this layer, the operation is done to monitor the hardware by the sensors. Implementation of the proposed model is done in the Ns2 simulator. It is also worth mentioning that in this simulation, the intention is to use the sensor in the water supply network with the consideration of the Gps module to send information about the equipment and hardware available on the network. Online control of information is done using the Internet of Things. In order to set up and simulate a network, the user writes an application in the programming language Tcl, in which details of the components of the computer network are determined, the connections and the method of communication of the nodes of the computer network with each other are specified, and computer network topology is defined. Then, using scheduling functions, the source generates traffic and the start and end time of sending packets and the scheduling of all network events are determined. Finally, the simulation is made by executing OTcl script by NS2 software. When setting up a network, the user sets up the data path by setting the pointer of the thing of network to the suitable neighbor thing. When a user wants to create a new network thing, he can easily write codes for that new thing or create a hybrid network thing using the library of things. In the above environment, we define a number of sensors to collect the data we want, given the fact that there is no water leakage definition in Ns2, we assume the data is sent by the sensor. The data sent by the sensor is collected, then the data is transmitted in the network, and finally the output is provided as a $\mathrm{Tr}$ file and we examine the parameters by calling the Tr file in Matlab. In the second stage, we describe the events and define the crisis in the water supply network. One of the primary causes of a catastrophic disaster is a shock factor, which means that sudden accidents bring a lot of pressure to the people, society and the organizations and disturb the balance of the people. Experience has shown that predetermined planning for dealing with disasters can significantly reduce social disturbances, required for having information. Information gathering in the pre and post-accident and crisis situations will not be difficult because the affected community will become overwhelmed and will be able to collect information from responsible organizations and institutions. However, during the incident and crisis and as long as the society is in critical condition, information gathering such as: volume of damages, damaged areas, hazardous areas, distribution of damage, distribution of resources and facilities, prioritization of areas in terms of service, the volume of services required and ... will be very helpful and, at the same time, very difficult. Therefore, given the lack of appropriate tools and technology in the country to collect information in critical situations, and in particular in the water and wastewater area, we need to provide a seamless, coherent and locally managed plan for managing incidents.

In the management of accidents, after a disaster and crisis, and with the commencement of operations, each incident is divided into two parts: managerial and operational. The management department has the task of analyzing data, guidance, guidance, basic decision-making and advisory groups, and the operational department is required to collect data, disaster relief and disaster relief. A problem mentioned here is the gap between management and operation section and this gap will be solved only through exchange of data and information and considered as an information in this plan [8].

Levels of accidents include:

Code 0:

- Quantitative and qualitative events of water supply and sewage substations of Subscribers 
- Quantitative and qualitative events of water distribution network (diameter less than 60 $\mathrm{mm})$

Code 1: Quantitative and qualitative events of water distribution network (diameter larger than $60 \mathrm{~mm}$ )

Code 2: Quantitative and qualitative events of water transmission network (Transmission lines between tanks, between tanks and refineries and between refineries and ponds wells water collection lines)

Code 3: Quantitative and qualitative events for water supply facilities (Pond, water treatment plant, water tanks, pumping stations, wells, chlorination systems, water desalinators)

Code 4: Incident events (Ground level leakage, water or sewage leakage in the metro or tunnel, earthquake, storm, flood, vandalism, explosion, etc.,)[1]

In the third step, in order to control the intelligent hardware equipment that can send the signal at the time of the incident in the water supply network, we will outline the necessary items, it should be noted that due to the fact that at the time of the incident in the water supply network, the possibility of the end of the accident is not fully automated and intelligent and the presence of manpower will be necessary to carry out the necessary operations. It cannot be said that an accident can be completed by one hundred percent of intelligence, and intelligent item in the information management of an incident through communication with the necessary databases to retrieve incident data such as location, cause, required operations, communication with managers, Communication with operational forces can be defined as little as possible. To this end, the link between the central server of the water supply equipment hardware and the GIS database, the bank of the officers, the bank of managers, the subscriber bank should also be identified. In the fourth step, we will provide a mobile platform for managing an accident. In the following, after defining the 5-layer reference architecture, the separation of the water supply network hardware, the definition of the communications needed to intelligently identify the incident information, in this step, to view the events of the water supply network, the data collected through the Internet of things are transmitted to the MySQL database via the Internet. The PHP API runs on the central server and connects to the MySQL database and returns the data in accordance with the query defined as a simple HTML page in the form of Java Script Object Notation (json). An Android software is developed in the Eclipse IDE using Java and has Internet connection permissions to connect to Wi-Fi. Data from the database (based on MySQL) can be obtained by clicking on the software developed on the mobile phone. When the application is clicked, then this program connects to the URL of the PHP API. As a result, the PHP API connects to the database and returns the data to the mobile phone. Here, the intention is to use the sensor in the water supply network with the Gps module to send information and to evaluate the important parameters of delay, permeation and packets in the two proposed and the traditional seven-layer OSI models. And according to the results obtained at one of the levels of disaster recovery, we will use the proposed architecture. For more intelligent management and coordination at the time of the incident and receiving the signal from the equipment or hardware mentioned in the previous section, the following communications as shown in Figure 3 are also necessary. 


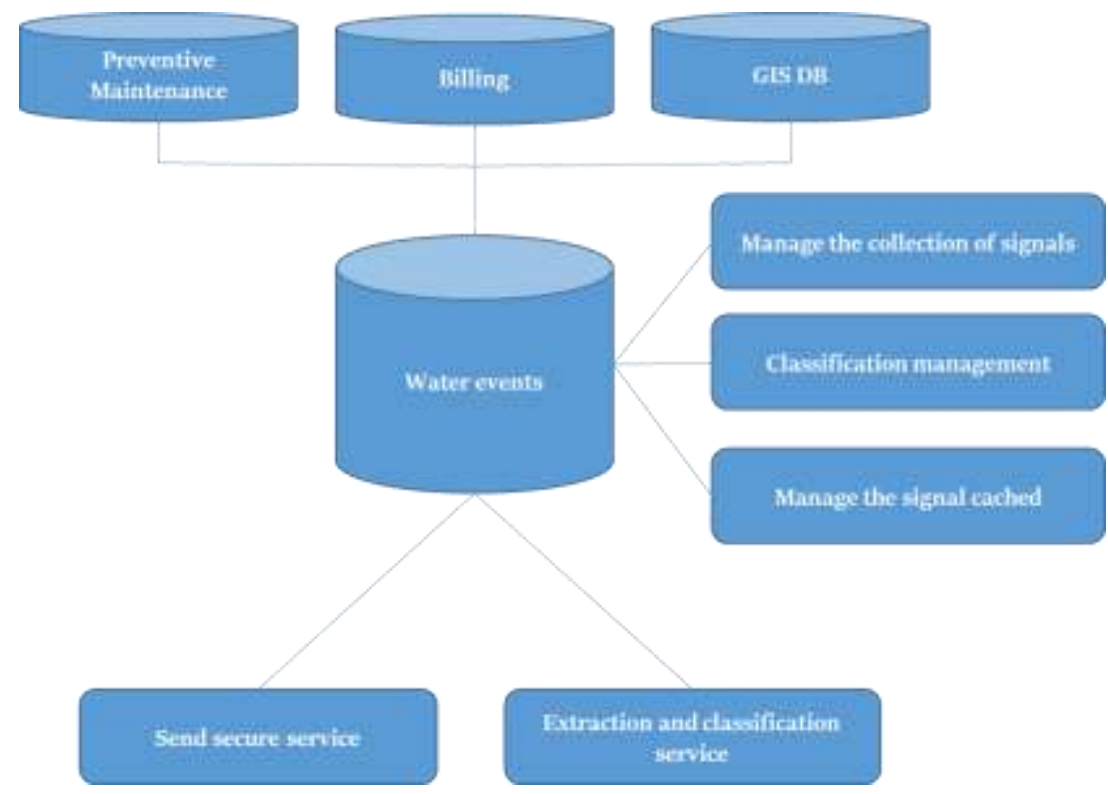

Figure 3. Connection of Required Databases

In the networks of water supply, facilities and equipment that can control and send the signal are as Pumping stations, water treatment plant, Main transmission lines, Tanks, Wells, Sensitive stations; It should be noted that in the Internet of Things hardware is chosen that, in addition to the ability to send a signal, has the possibility to define parameters with the ability to measure at the time of the incident and acts to send signal based on the periodic measurements of the parameters [8].

This section may be divided by subheadings. It should provide a concise and precise description of the experimental results, their interpretation as well as the experimental conclusions that can be drawn.

\section{Proposed Plan}

In this section, we use the Internet-based regulatory framework for industrial objects to manage an accident in the water network, where the state of the equipment is collected by mobile devices and sensors and safely sent to the cloud for access by professionals. Signal upgrade methods, Watermarking, and other related analytics are used to prevent identity theft or error. The architecture of the regulatory framework is shown in Figure 4. The flow of information in this architecture is that the information of the hardware equipment that is measurable and controlled by the water network is recorded by the interconnected equipment such as sensors; then, after applying the methods of rebuilding and enhancing the signal, and Watermarking the data, it will be sent to cloud data centers through network connections. The cloud system validates this information whether the information is correct, then extracts some of the features from the data and categorizes the signal and sends it to the relevant specialists and managers using software to provide solutions for specific events. 


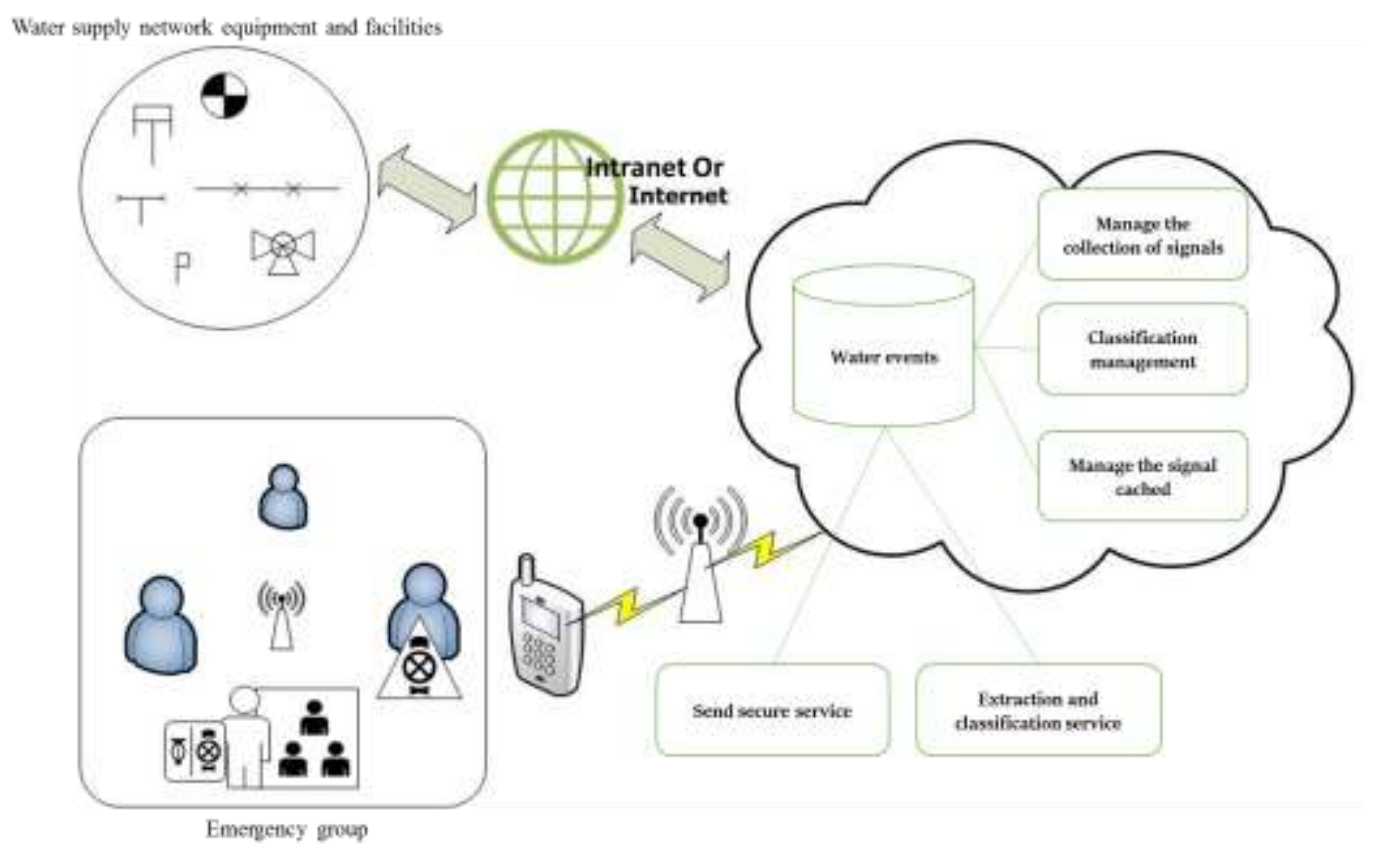

Figure 4. Diagram of the Regulatory Framework Architectural

\section{Simulation Results}

The intention is to use the sensor in the water supply network with the GPS module to send information and to evaluate the important parameters of delay, permeation and packets in the two proposed and traditional seven-layer OSI models. According to the results obtained at one of the levels of disaster recovery, we will use the proposed architecture.

Figure 5 shows the Comparison between the output of the proposed model and the OSI model in terms of PDR, as you can see, we performed the simulation in 200 seconds and the output of the proposed model is optimal compared to the OSI model.

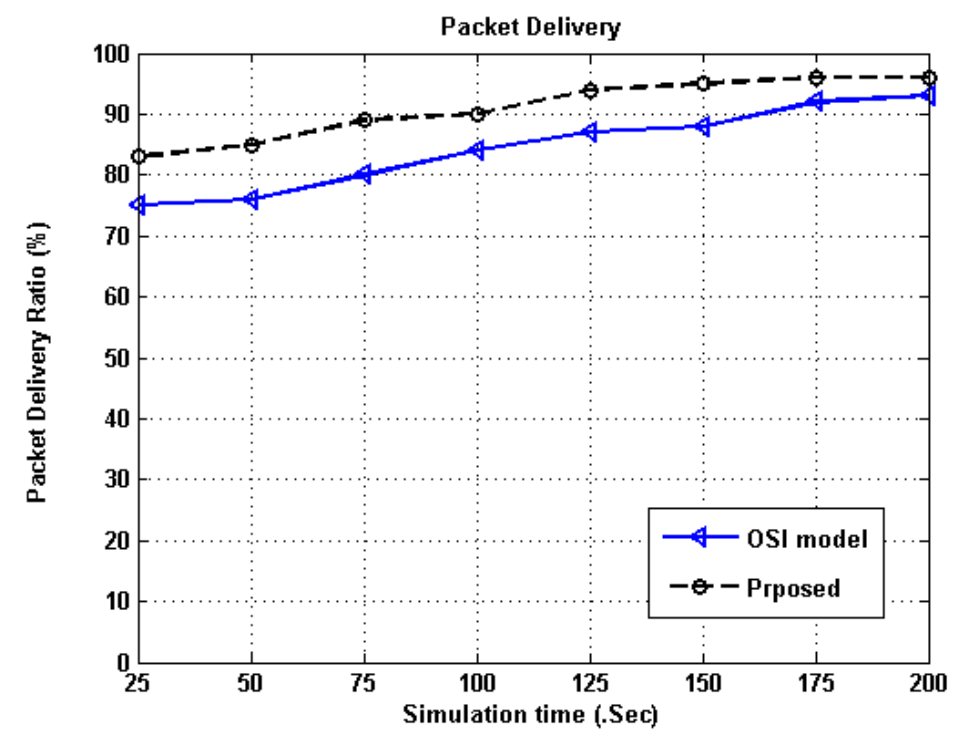

Figure 5. Comparison of PDR 
Figure 6 shows the Comparison between the output of the proposed model and the OSI model in terms of overhead, as you can see, overhead in the proposed method is not optimized for the OSI model, due to the higher computational complexity in the proposed model.

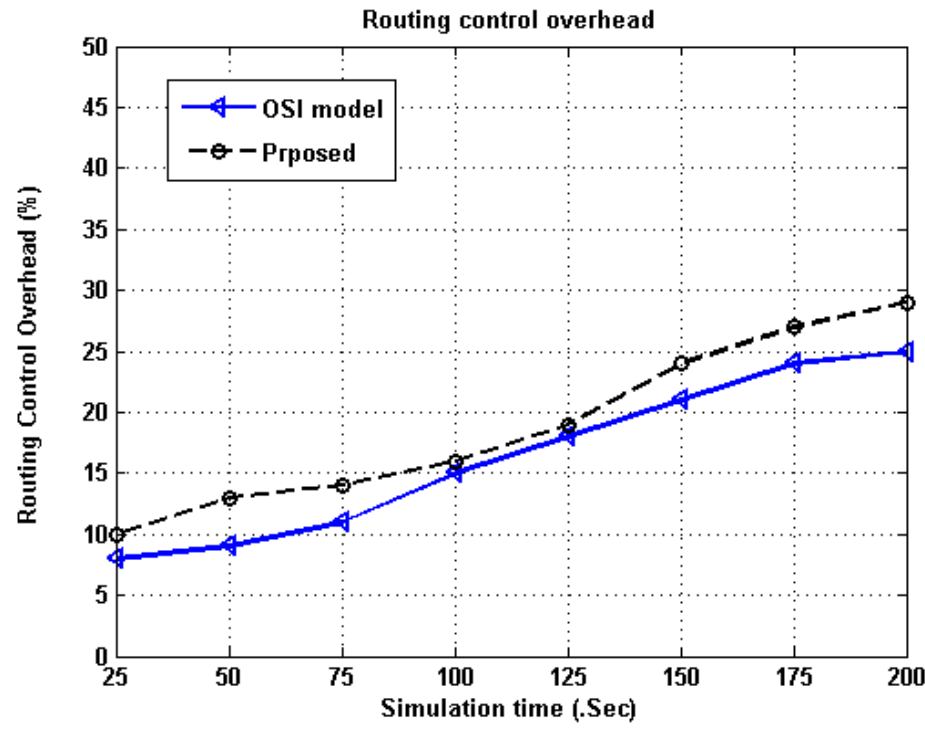

Figure 6. Comparison of Overhead

Figure 7 shows the comparison between the output of the proposed model and the OSI model in terms of Transmission Delay, as you can see, the transmission delay in the proposed method is optimized relative to the OSI model.

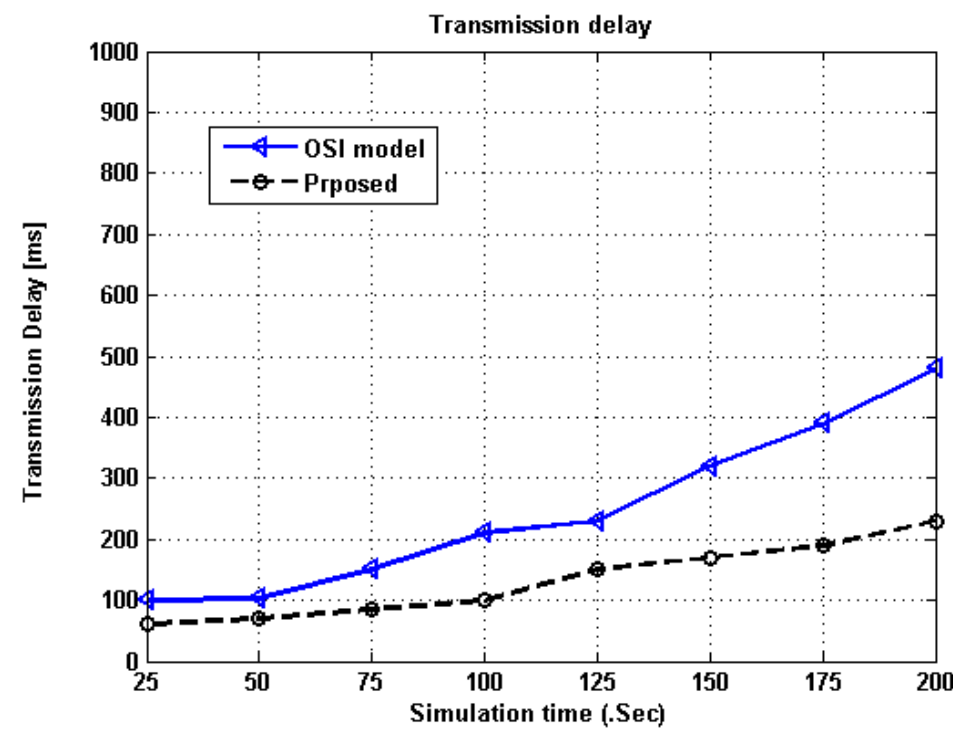

Figure 7. Comparison of Transmission Delay

Figure 8 shows the comparison between the output of the proposed model and the OSI model in terms of Packets Drop, as you can see, the operating power in the proposed method is optimized relative to the OSI model. 


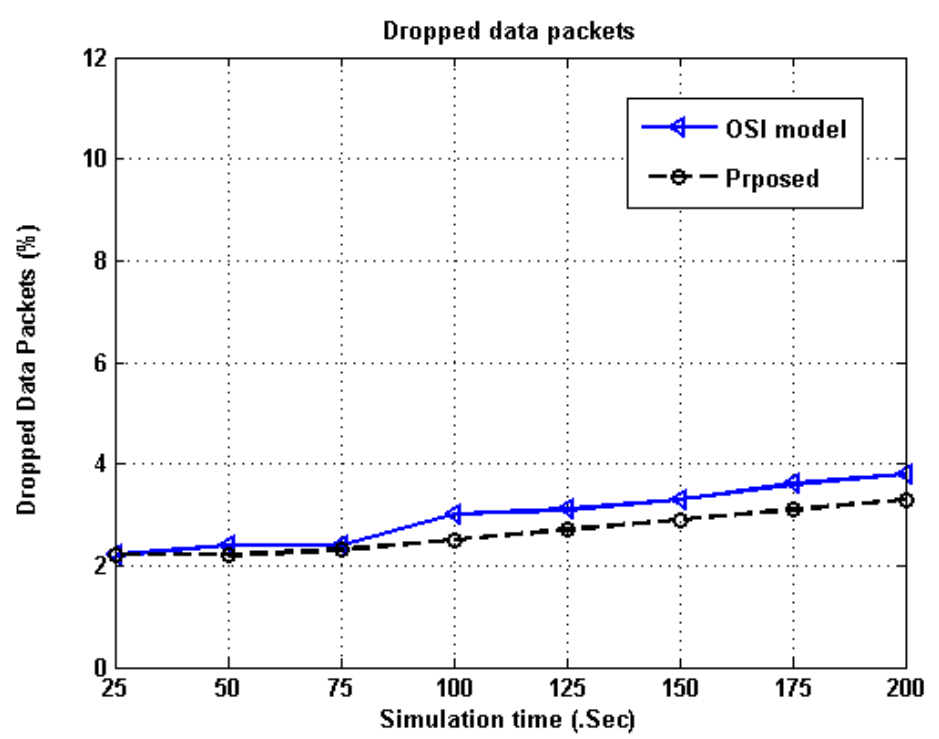

Figure 8. Comparison of Packets Drop

Figure 9 shows the change of the TCP Packet Size from 32 bytes to 4096 bytes and comparison between the output of the proposed model and OSI model for PDR, as you can see, the permeation in the proposed method is optimized relative to the OSI model.

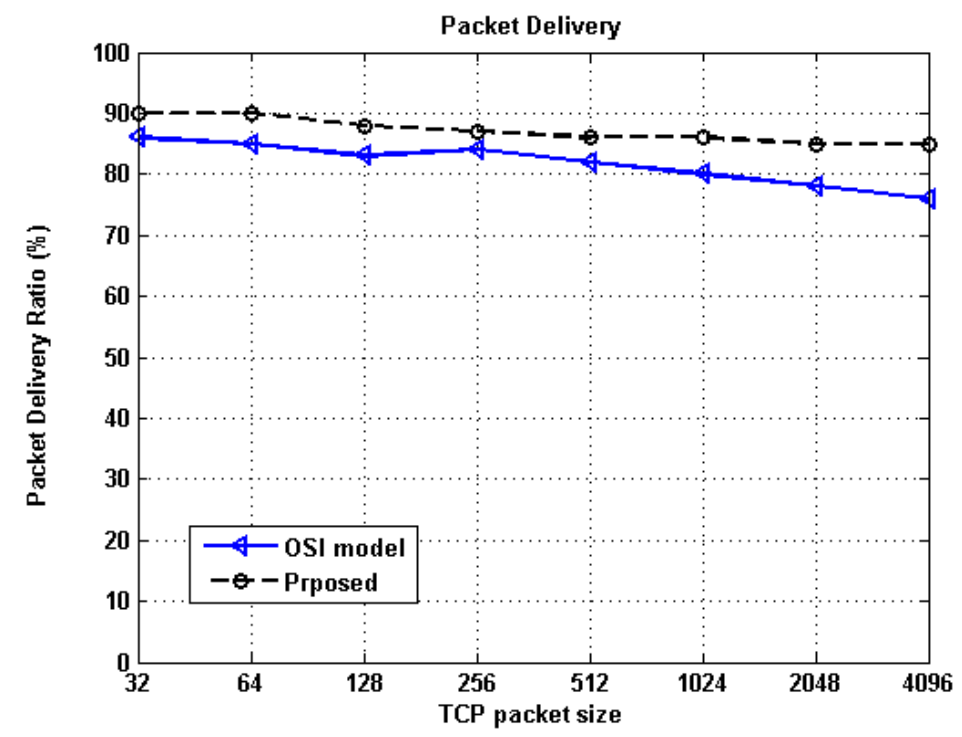

Figure 9. Comparison of PDR with Change Packet Size

Figure 10 shows the Change of the TCP Packet Size from 32 bytes to 4096 bytes and comparison between the output of the proposed model and OSI model in terms of Transmission Delay, as you can see, the transmission delay in the proposed method is optimized relative to the OSI model. 


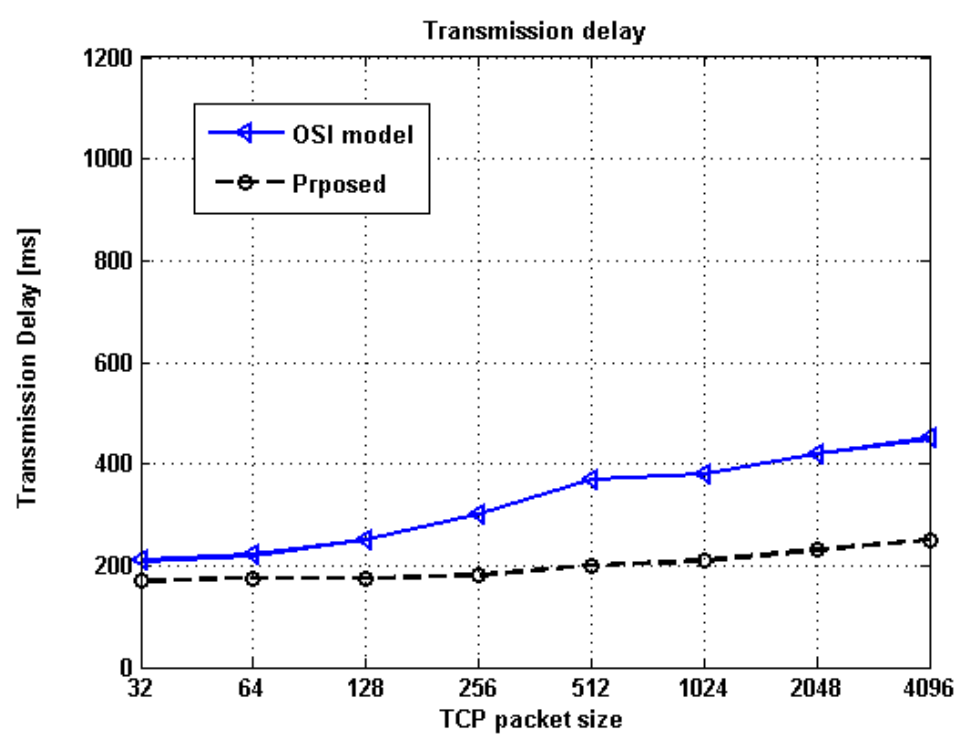

Figure 10. Comparison of Transmission Delay with Change Packet Size

Figure 11 shows the change of the TCP packet size from 32 bytes to 4096 bytes and comparison between the output of the proposed model and OSI model in terms of overhead, as you can see, the overhead in the proposed method is not optimized for the OSI model.

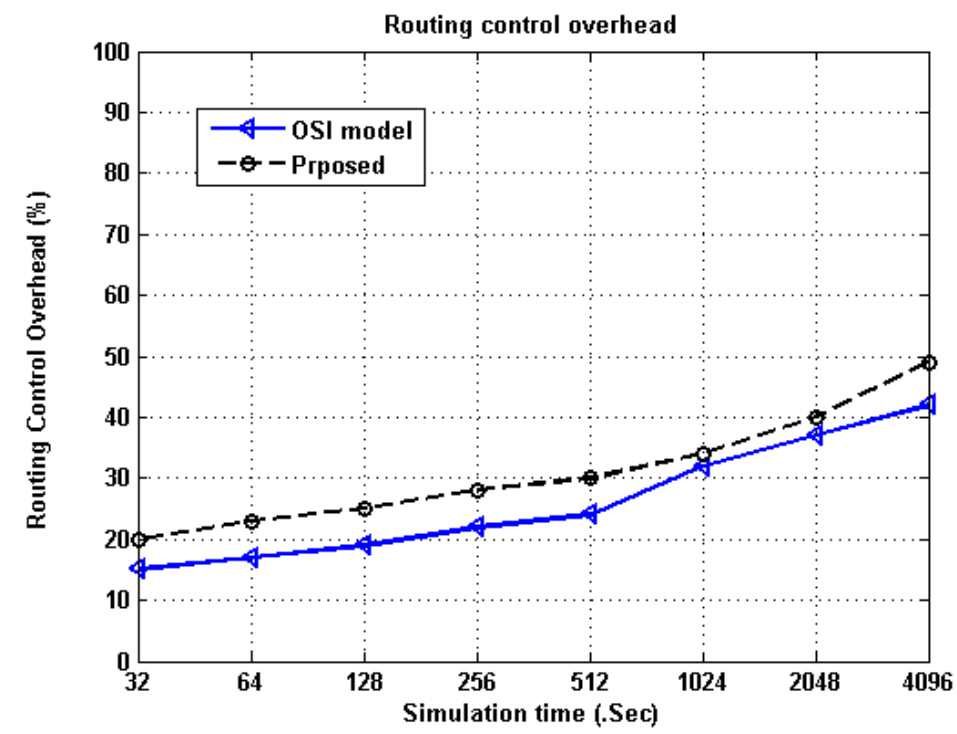

Figure 11. Comparison of Overhead with Change of the TCP Packet Size

Figure 12 shows the change of the TCP packet size from 32 bytes to 4096 bytes and comparison between the outputs of the proposed model with the OSI model in terms of Packets Drop, as you can see, the performance of the proposed method is optimized relative to the OSI model. 


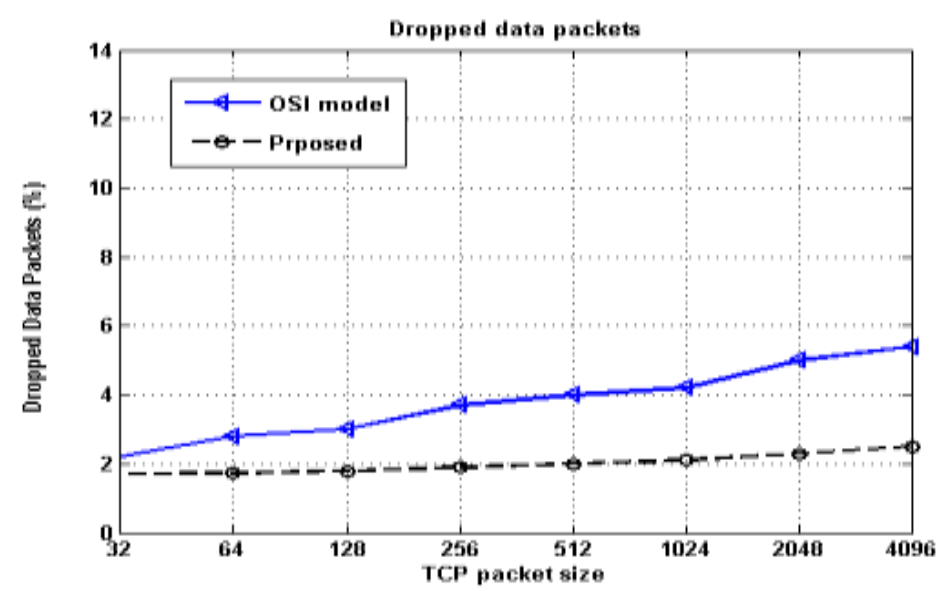

Figure 12. Comparison of Packets Drop with Change of the TCP Packet Size

The results of the disaster recovery process in the previous waterway network are as follows in Table1.

\section{Table1. Average Time to Handle Water Accidents in Water and Wastewater Network in the Former Way}

\begin{tabular}{|c|c|c|c|c|c|c|}
\hline Region & $\begin{array}{l}\text { Average time } \\
\text { between } \\
\text { announcement } \\
\text { and dispatch }\end{array}$ & $\begin{array}{l}\text { Average } \\
\text { time } \\
\text { difference } \\
\text { between the } \\
\text { dispatch } \\
\text { time and the } \\
\text { action }\end{array}$ & $\begin{array}{l}\text { average time } \\
\text { difference } \\
\text { between the } \\
\text { steps is up to } \\
\text { completion }\end{array}$ & $\begin{array}{l}\text { Average time } \\
\text { difference } \\
\text { between the } \\
\text { announcement } \\
\text { and the } \\
\text { completion }\end{array}$ & $\begin{array}{c}\text { The } \\
\text { average } \\
\text { notice } \\
\text { period } \\
\text { until the } \\
\text { end of the } \\
\text { work }\end{array}$ & $\begin{array}{l}\text { count } \\
\text { of } \\
\text { crisis }\end{array}$ \\
\hline Region 1 & $9 \mathrm{Min}$ & $41 \mathrm{Min}$ & $31 \mathrm{Min}$ & 1 Hour 21 Min & $\begin{array}{c}1 \text { Hour } 36 \\
\text { Min }\end{array}$ & 7595 \\
\hline Region 2 & $11 \mathrm{Min}$ & $24 \mathrm{Min}$ & 29 Min & 1 Hour 5 Min & $\begin{array}{c}1 \text { Hour } 13 \\
\text { Min }\end{array}$ & 8997 \\
\hline Region 3 & 27 Min & $51 \mathrm{Min}$ & 46 Min & 2 Hour 4 Min & $\begin{array}{c}2 \text { Hour } 24 \\
\text { Min }\end{array}$ & 7017 \\
\hline Region 4 & $20 \mathrm{Min}$ & $40 \mathrm{Min}$ & 44 Min & 1 Hour 46 Min & $\begin{array}{c}2 \text { Hour } 21 \\
\text { Min }\end{array}$ & 7017 \\
\hline Region 5 & 14 Min & 43 Min & 31 Min & 1 Hour 29 Min & $\begin{array}{c}2 \text { Hour } 12 \\
\text { Min }\end{array}$ & 9864 \\
\hline Region 6 & $10 \mathrm{Min}$ & $31 \mathrm{Min}$ & $24 \mathrm{Min}$ & 1 Hour 6 Min & $\begin{array}{c}1 \text { Hour } 48 \\
\text { Min }\end{array}$ & 10247 \\
\hline Region 7 & 20 Min & 41 Min & 2 Hour 1 Min & 3 Hour 3 Min & 4 Hour & 4151 \\
\hline Region 8 & 16 Min & 37 Min & $42 \mathrm{Min}$ & 1 Hour 36 Min & $\begin{array}{c}1 \text { Hour } 47 \\
\text { Min }\end{array}$ & 13841 \\
\hline Region 9 & 1 Hour 4 Min & 31 Min & $58 \mathrm{Min}$ & 2 Hour 34 Min & $\begin{array}{c}2 \text { Hour } 55 \\
\text { Min }\end{array}$ & 13922 \\
\hline Region 10 & 1 Hour 1 Min & $\begin{array}{c}1 \text { Hour } 19 \\
\text { Min }\end{array}$ & $\begin{array}{c}1 \text { Hour } 12 \\
\text { Min }\end{array}$ & 3 Hour 33 Min & $\begin{array}{c}3 \text { Hour } 52 \\
\text { Min }\end{array}$ & 10443 \\
\hline $\begin{array}{l}\text { Weighted } \\
\text { average }\end{array}$ & 27 Min & $41 \mathrm{Min}$ & $46 \mathrm{Min}$ & 1 Hour 56 Min & $\begin{array}{c}2 \text { Hour } 21 \\
\text { Min }\end{array}$ & 93094 \\
\hline
\end{tabular}

By following the above model and using the Internet in dealing with blueprints and simulations in the real water network, the following results were obtained (Table 2. Average time to handle water accidents in water and wastewater Network With IOT), which shows the impact of up-to-date equipment and the use of IOT technology in disaster recovery. As you can see, the average time of disaster recovery is reduced during use IOT. 


\section{Table 2. Average Time to Handle Water Accidents in Water and Wastewater Network with IOT}

\begin{tabular}{|c|c|c|c|c|c|c|}
\hline Region & $\begin{array}{l}\text { Average time } \\
\text { between } \\
\text { announcement } \\
\text { and dispatch }\end{array}$ & $\begin{array}{l}\text { Average } \\
\text { time } \\
\text { difference } \\
\text { between the } \\
\text { dispatch } \\
\text { time and the } \\
\text { action }\end{array}$ & $\begin{array}{l}\text { average time } \\
\text { difference } \\
\text { between the } \\
\text { steps is up to } \\
\text { completion }\end{array}$ & $\begin{array}{l}\text { Average time } \\
\text { difference } \\
\text { between the } \\
\text { announcement } \\
\text { and the } \\
\text { completion }\end{array}$ & $\begin{array}{c}\text { The } \\
\text { average } \\
\text { notice } \\
\text { period } \\
\text { until the } \\
\text { end of the } \\
\text { work }\end{array}$ & $\begin{array}{l}\text { count } \\
\text { of crisis }\end{array}$ \\
\hline Region 1 & $6 \mathrm{Min}$ & 31 Min & 19 Min & 58 Min & $\begin{array}{c}1 \text { Hour } 12 \\
\text { Min }\end{array}$ & 6939 \\
\hline Region 2 & $8 \mathrm{Min}$ & 25 Min & 28 Min & 1 Hour 2 Min & $\begin{array}{c}1 \text { Hour } 9 \\
\text { Min }\end{array}$ & 9655 \\
\hline Region 3 & 22 Min & 39 Min & 38 Min & 1 Hour 41 Min & $\begin{array}{c}1 \text { Hour } 55 \\
\text { Min }\end{array}$ & 8320 \\
\hline Region 4 & 13 Min & 24 Min & 33 Min & 1 Hour 11 Min & $\begin{array}{c}1 \text { Hour } 41 \\
\text { Min }\end{array}$ & 6282 \\
\hline Region 5 & 12 Min & 39 Min & 31 Min & 1 Hour 23 Min & $\begin{array}{c}1 \text { Hour } 57 \\
\text { Min }\end{array}$ & 10549 \\
\hline Region 6 & 7 Min & 26 Min & $21 \mathrm{Min}$ & $55 \mathrm{Min}$ & $\begin{array}{c}1 \text { Hour } 35 \\
\text { Min }\end{array}$ & 9777 \\
\hline Region 7 & 15 Min & 56 Min & 57 Min & 2 Hour 9 Min & $\begin{array}{c}2 \text { Hour } 36 \\
\text { Min }\end{array}$ & 3514 \\
\hline Region 8 & 14 Min & 48 Min & 34 Min & 1 Hour 37 Min & $\begin{array}{c}1 \text { Hour } 54 \\
\text { Min }\end{array}$ & 11391 \\
\hline Region 9 & 1 Hour 5 Min & 34 Min & 44 Min & 2 Hour 25 Min & $\begin{array}{c}2 \text { Hour } 39 \\
\text { Min }\end{array}$ & 15364 \\
\hline Region 10 & 20 Min & 40 Min & 38 Min & 1 Hour 39 Min & $\begin{array}{c}1 \text { Hour } 51 \\
\text { Min }\end{array}$ & 11576 \\
\hline $\begin{array}{l}\text { Weighted } \\
\text { average }\end{array}$ & $21 \mathrm{Min}$ & 35 Min & 33 Min & 1 Hour 32 Min & $\begin{array}{c}1 \text { Hour } 52 \\
\text { Min }\end{array}$ & 93367 \\
\hline
\end{tabular}

\section{Conclusion}

The results show that the five-layer model is optimized for power parameters, transmission delay, and permeation for managing drinking water crisis. Also, as you can see, the average response time and incident handling are reduced due using IoT. At the time of the incident and sending the signal to the database by categorizing the received signal and sending a secure output to the Android application, the user, the unit or smart equipment incident in the water network using management data and Operates intelligently in a shorter time, because the management data of an incident or crisis on the mobile platform allows for the exchange of information between senior executives and the On Call administrator, the operational data are used for incident and signal information received and routing to the location of the crisis for the relief forces. The goal here is to handle an incident with the least amount of time and complete the relevant forms on the cell phone and store it in cloud. In addition, the following points can be used to indicate the point of research: In the events of the water supply network, using the management, classification and sending of output information on mobile phones and using the items defined in the software, we will see reduction of incident time, improve decision speed, management of labor division and reduce costs. Using the 5-layer architecture of the Internet of things in the network of a critical industry can affect the performance of organizational processes. Smartization has been presented through the management of various technologies in five layers and in the context of mobile can be considered as an influential achievement in the water industry. 


\section{References}

[1] Tehran Province Water and Wastewater Company. Available online: www.tpww.ir, Disaster Implementation Style sheets, (2017).

[2] D. P. F Möller, "Introduction to the Internet of Things", in Guide to Computing Fundamentals in CyberPhysical Systems, Computer Communications and Networks, Springer, (2016), pp. 141-184.

[3] F. Khodadadi, A. V. Dastjerdi and R. Buyya, "Internet of Things: an overview", Internet of Things, Chapter 1, (2016), pp. 3-27.

[4] S. M Banu, L. M Dascălu and G. Toacşe, "Internet of Things in Psoriasis Assessment and Treatment", Part of the IFIP Advances in Information and Communication Technology, vol. 394, (2013), pp. 172179.

[5] A. Al-Fuqahaand, M. Guizaniand and M. Mohammadia, "In IEEE Communication Surveys \& Tutorials", vol. 17, no. 4, (2015), pp. 2347-2376.

[6] M. Bhayani and M. PatelChintan, "Internet of Things (IoT): In a Way of Smart World", Chapter from book Proceedings of the International Congress on Information and Communication Technology: ICICT, vol. 1, (2015), pp. 343-350.

[7] www.slideshare.net. Available online: https://www.slideshare.net/rotemshemesh/the-smart-waternetwork-revolution-15230313, "The Smart water network revolution".

[8] Water and Wastewater Company of Iran, Available online: www.nww.ir, Report on Strategic Studies on the Establishment of the SCADA System, (2016).

\section{Authors}

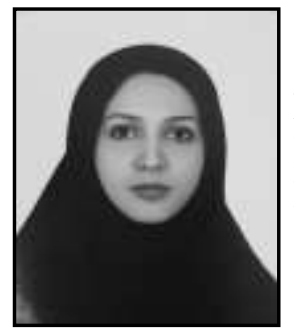

Azar Astanehparast, received her B.Sc. degree in computer software engineering. She is currently a M.Sc. Student in Computer Engineering Department, Yadegar-e-Imam Khomeini (RAH) Shahre Rey Branch, IAU University, Tehran, Iran under the supervision of Prof. Dr. Haghparast. She has been engaged in research in the field of cloud computing and Internet of Things.

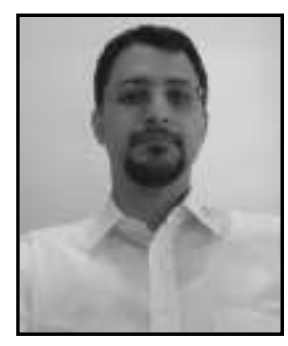

Majid Haghparast, received his B.Sc. in computer hardware engineering in 2003. He received his M.Sc. and Ph.D. degrees in computer architecture in 2006 and 2009, respectively. Since 2007, he has been affiliated with the Computer Engineering Faculty, Yadegare-Imam Khomeini (RAH) Shahre Rey Branch, IAU University, Tehran, Iran. His research interests include computer arithmetic and reversible logic circuits. Since April 2017 he is conducting his sabbatical at the Johannes Kepler University Linz, Austria, where he also is a Research Fellow. Dr. Haghparast is on the panel of reviewers for various international journals.

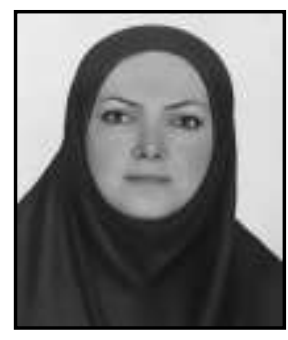

Sara Najafzadeh, received her M.Sc. degree in computer engineering from Iran University of Science and Technology in 2007 and Ph.D. degree from Universiti Teknologi Malaysia (UTM) Johor, Malaysia in 2014. In 2015, she joined the Computer Engineering Faculty, Yadegar-e-Imam Khomeini (RAH) Shahre Rey Branch, IAU University, Tehran, Iran as an assistant professor. Her current research interests include Cloud computing and Internet of Things. She is an author for many conference, journal papers and book chapters. 